\title{
HEREDITARY MALFORMATIONS IN MAN *
}

\author{
TAGE KEMP \\ University Institute for Human Genetics, Copenhagen
}

Received 23.v.47

SERIOUs congenital physical malformations, especially skeletal, occur in at least one per cent. of all newborn children. On account of the great mortality for these affections, they are less frequent in the total population. A majority of these congenital lesions are hereditary, but this does not apply to all of them. Some of them, for instance, may be sequelæ of injury early in fœtal life ; for example, deformities from constriction by amniotic cords (fig. I), double-monster (fig. 2), acardia in twin pregnancy (fig. 3), or they may be due to serological disharmony between the mother and the fotus (e.g. in rhesus-negative mothers), to infections (e.g. with rubella or toxoplasmosis) or to intoxications during pregnancy.

It is the hereditary malformations that I shall mention herenot in a systematic review, but those conditions investigated in the Institute of Human Genetics in Copenhagen in recent years-which have proved to be of particular genetic interest. For, as a matter of fact, these physical malformations constitute the group of hereditary affections that are most suitable for genetic investigation. They are congenital, and they are demonstrable throughout life; further, they are easy to recognise from their description by laymen. Their occurrence can therefore be followed back through many generations, and pedigrees of their inheritance are relatively easy to establish. Indeed, the first lesion for which Mendelian inheritance was demonstrated, was a physical malformation-namely, brachydactyliawhich Farabee in 1905 described as a dominant inherited lesion in three large families in which altogether 99 members presented the malformation.

It has been practicable later, through the study of other bodily malformations, to show that the laws of heredity which we know from experimental genetics apply correspondingly also to hereditary lesions in man.

As an example of the numerous congenital malformations of the skull a family with craniofacial dysostosis (Crouzon's disease) is shown

* A paper read before The Genetical Society in London, 25th November $194^{6}$. 
(plate II, fig. 5, and pedigree I). A woman with Crouzon's disease, without any known cases of the disease among her ascendants, had in all five children in two different marriages-by her first husband one normal daughter and one daughter with Crouzon's disease, by her second husband one son with Crouzon's disease and a pair of dizygotic twins, a normal girl and a boy with Crouzon's disease. The pedigree confirms the view advanced by Apert in 1907, that this disease may arise from mutation as a dominant hereditary affection. So far, however, the mutation rate for this rather rare disease has not been calculated. I should consider it impossible in a small country like Denmark to collect a sufficient number of cases for this purpose.

Harelip and cleft palate are very common malformations, and a hereditary disposition is the essential etiologic factor. There are, as shown by Fogh-Andersen, two different malformations with no genetic connection, viz. (I) harelip with or without associated cleft palate

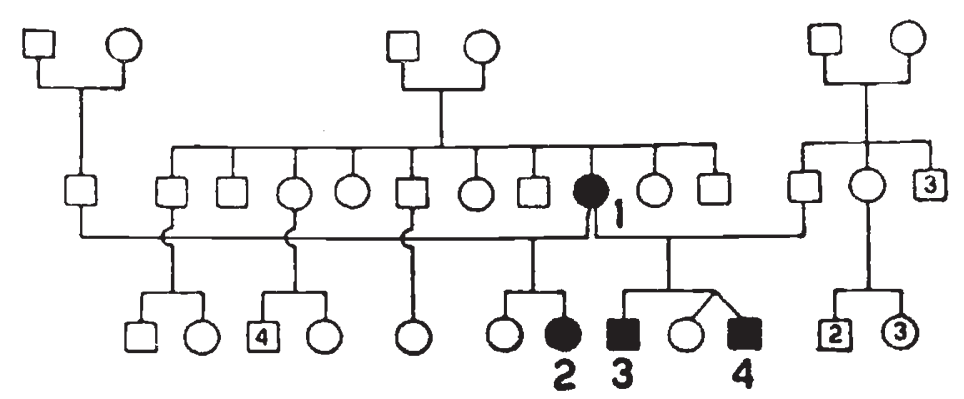

Pedigree $\mathrm{x}$. Craniofacial dysostosis. The disease has probably arisen through mutation in number $\mathrm{x}$.

(ha. $(+$ cl. pa. $)$ and (2) isolated cleft palate (cl. pa.). The frequency at birth of these malformations in Denmark is $1 \cdot 50$ per mille $(\stackrel{+}{+}$ $0 \cdot$ I I per mille), viz. I I per mille ha. (+cl. pa.) and 0.4 per mille isolated cl. pa. Twenty-five per cent. of the children born with harelip or cleft palate die within the first year of their birth, and ro per cent. of them have at birth severe associated malformations. Among the relatives of patients with harelip and cleft palate, however, no definitely increased occurrence of other affections is found.

Fogh-Andersen has determined the empirical figures of genetic prognosis for the different groups of relatives by an enumeration according to the propositus method, The figures are :-

for ha. $(+c l . p a$.$) :$

Frequency among children of ha. ( + cl. pa.) patients $2 \cdot 0$ per cent. Frequency among sibs, when parents normal . . 4.4 ",

Frequency among sibs, when one parent has ha.

$$
\text { (+ cl. pa.) . . . . . . } 14.0 \text {, }
$$


for isolated $c l . p a$. :

Frequency among children of cl. pa. patients, if hereditarily disposed (otherwise probably far smaller) . $\cdot$. $\cdot$. .

Frequency among sibs, when parents normal and if hereditarily disposed

$7 \cdot 0$ per cent.

Frequency among sibs without known hereditary disposition

Frequency among sibs, when one parent has cl. pa. . I $7^{\circ} 0$,

The twin material permits of no exact determination of the degree of manifestation, but it seems to be much below 50 per cent. Pl. II, figs. 6-9, shows 3 pairs of identical twins with harelip and cleft palate ; in figs. 6 and 7 concordant and on left side in both twins (congruent); in fig. 8 concordant and reversed asymmetrical (mirror-imaging); and in fig. 9 discordant.

Most cases of ha. (+ cl. pa.) must be supposed to be hereditary, whereas in isolated $\mathrm{cl}$. pa. there is probably a considerable admixture of non-hereditary cases. The most likely manner of inheritance for ha. (+ cl. pa.) is that of "conditioned dominance" with sex limitation to males and considerably less manifestation of the heterozygote than of the homozygote, so that the affection is in some families apparently dominant ( $c f$. pedigree 2 ), more often, however, apparently of a recessive character ( $c f$. pedigree 3$)$.

These new results concerning the inheritance of harelip and cleft palate have been achieved by Fogh-Andersen. He examined a sample representative of the 4000 harelip and cleft palate patients in Denmark, including 500 ha. (+cl. pa.) patients and $200 \mathrm{cl}$. pa. patients and their families, using the statistical genealogical method known as Weinberg's "Proband" (propositi) method. When investigating the inheritance of more rare malformations it is not necessary to limit the study to a sample, it may be possible to collect all cases of the malformation in question living in the country. Trier Mørch's study of the chondrodystrophic dwarfs in Denmark may exemplify that.

Trier Mørch (I94I) examined all living (86) and 22 recently deceased chondrodystrophics in Denmark, and in addition a Swedish family. He concludes that all cases of chondrodystrophy are of genotypical nature, transmitted as a dominant character, arising rather frequently through mutation. When both parents are normal, chondrodystrophy will appear once in every 10,000-12,000 births. Pedigree 4 shows a case of chondrodystrophy probably arisen through mutation (the patient to the left in pl. III, fig. ro) ; his ascendants and all known members of the family were normal, and no consanguinity occurred in the pedigree. Normal mothers and fathers of chondrodystrophics are older than those of non-chondrodystrophics. 
have, however, shown that osteochondrodystrophy has to be divided into two forms :-

(I) Morquio's syndrome, which is inherited as a monogenic recessive, and in which the skeletal changes are localised largely in the vertebral column (fig. I I and pedigree 5).

(2) Silfverskiöld's syndrome, which is transmitted simply as a monogenic dominant character, and in which the skeletal changes

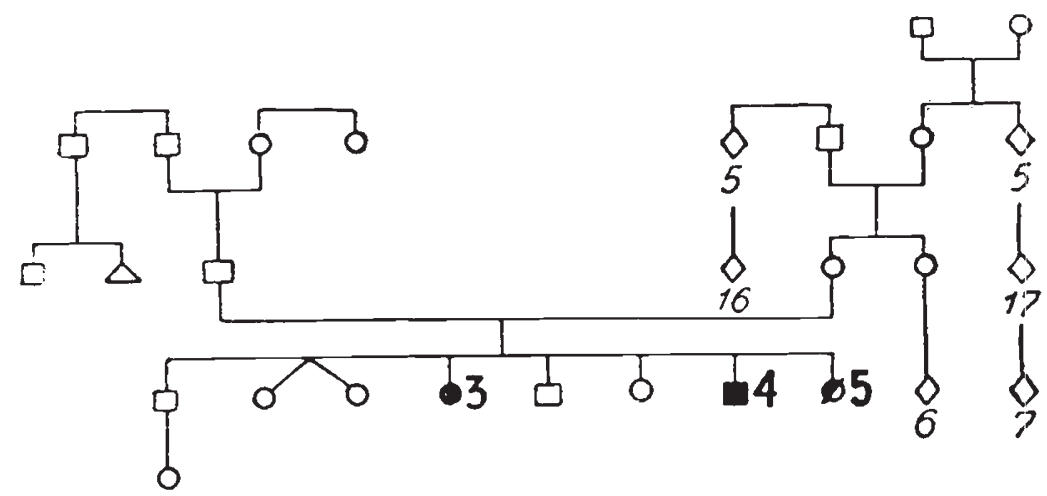

Pedigree 5. Osteochondrodystrophy (Morquio's syndrome) as a recessive character.

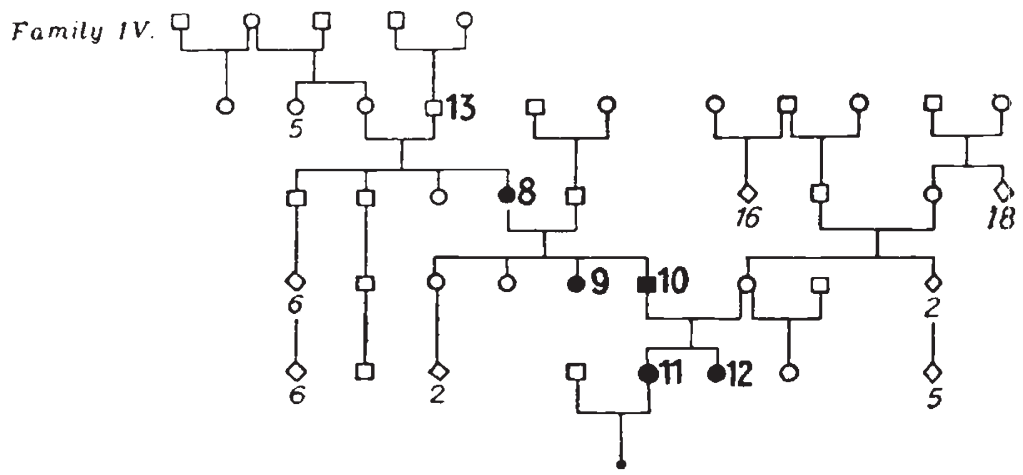

Pedigree 6. Osteochondrodystrophy (Silfverskiöld's syndrome) as a dominant chalacter.

(Pedigrees 5 and 6 from Helweg-Larsen and Trier Mørch).

are localised particularly in the extremities (fig. I 2 and pedigree 6). So far it has not been possible to calculate the mutation rate for Silfverskiöld's disease.

Arachnodactyly shows exactly the reversed symptoms of chondrodystrophy-long, slender acuminated extremities with spider-like fingers and toes and slim body, and often combined with luxatio lentis (Marfan's syndrome, pl. IV, fig. 13). Marfan's syndrome is inherited as a dominant character (pedigree 7); the disease is, however, very rare, and it has not therefore been possible so far to calculate the mutation rate. 
Another hereditary disease presenting generalised malformations of the bone is osteogenesis imperfecta (osteopsatyrosis, fragility of bones, Eddowe's disease). Fig. I4 shows a very severe case, which

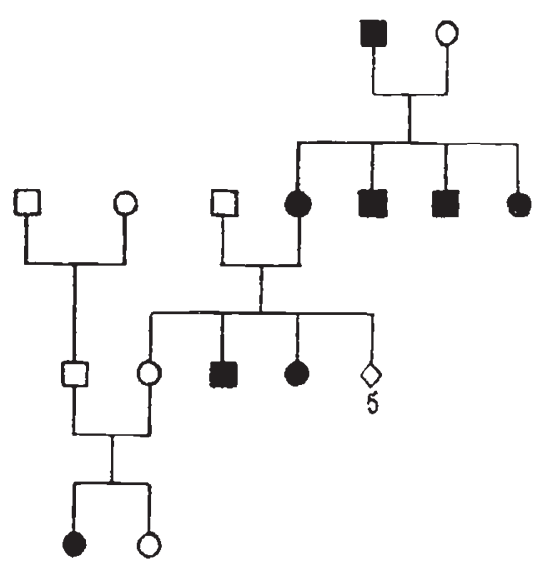

Pedigree 7. Arachnodactylia as a dominant character (from Filskov). occurred isolated in an otherwise normal family. The patient was a complete invalid during his whole lifetime. He had to stay in a hospital bedridden for many a long year; it is the reason why he did not propagate. Probably his disease had arisen through mutation. In fig. I5 a patient suffering from a less severe but yet a rather serious case of osteogenesis is seen; her family was normal but she herself had borne a child with osteogenesis. The patient on fig. I 6 had a still milder case of osteogenesis although he was an invalid; his mother, and her father and sister, suffered from osteogenesis. Apparently the disease was inherited as a dominant in this family. Thus the gene causing osteogenesis imperfecta varies considerably in manifestation, and again it has not been possible to calculate its mutation rate.

Eskelund and Bartels (194I) described a pair of identical male twins with spina bifida, born in Viborg,. Jutland, presenting a meningocele in the sacral region, eventration, abnormal development of the umbilical vessels, aplasia vesicæ, diastasis symphyseos, deformation of the columna vertebralis and pedes equino-varus (pl. I, fig. 4); this picture has been described by Aschoff as spina bifida umbalis.

Hindse-Nielsen (1938) investigated 124 families in Denmark with at least one case of craniorachischisis. Consanguineous marriage was found only three times among the 124 couples of parents. The greatest number showing the deformity in the same family was 7 , distributed among three groups of sisters and brothers. Among I 2,550 persons belonging to these 124 families, Hindse-Nielsen found $5^{\circ}$ extra cases of this deformity; in the 124 families were 131 sibships and these I 3 I propositi had in all $54^{8}$ brothers and sisters ; 28 (5. I per cent.) of these siblings had spina bifida aperta, a part of craniorachischisis. It is consequently probable that some hereditary component must be reckoned with in the genesis of this malformation ; it is not, however, a question of simple dominant or recessive heredity.

Some of the most severe malformations of the extremities are cleft hands and feet and other forms of ectrodactylia, and congenital amputations.

In Denmark, Birch-Jensen investigated 25-30 families with one or more cases of cleft hands. About 90 per cent. of the cases were 

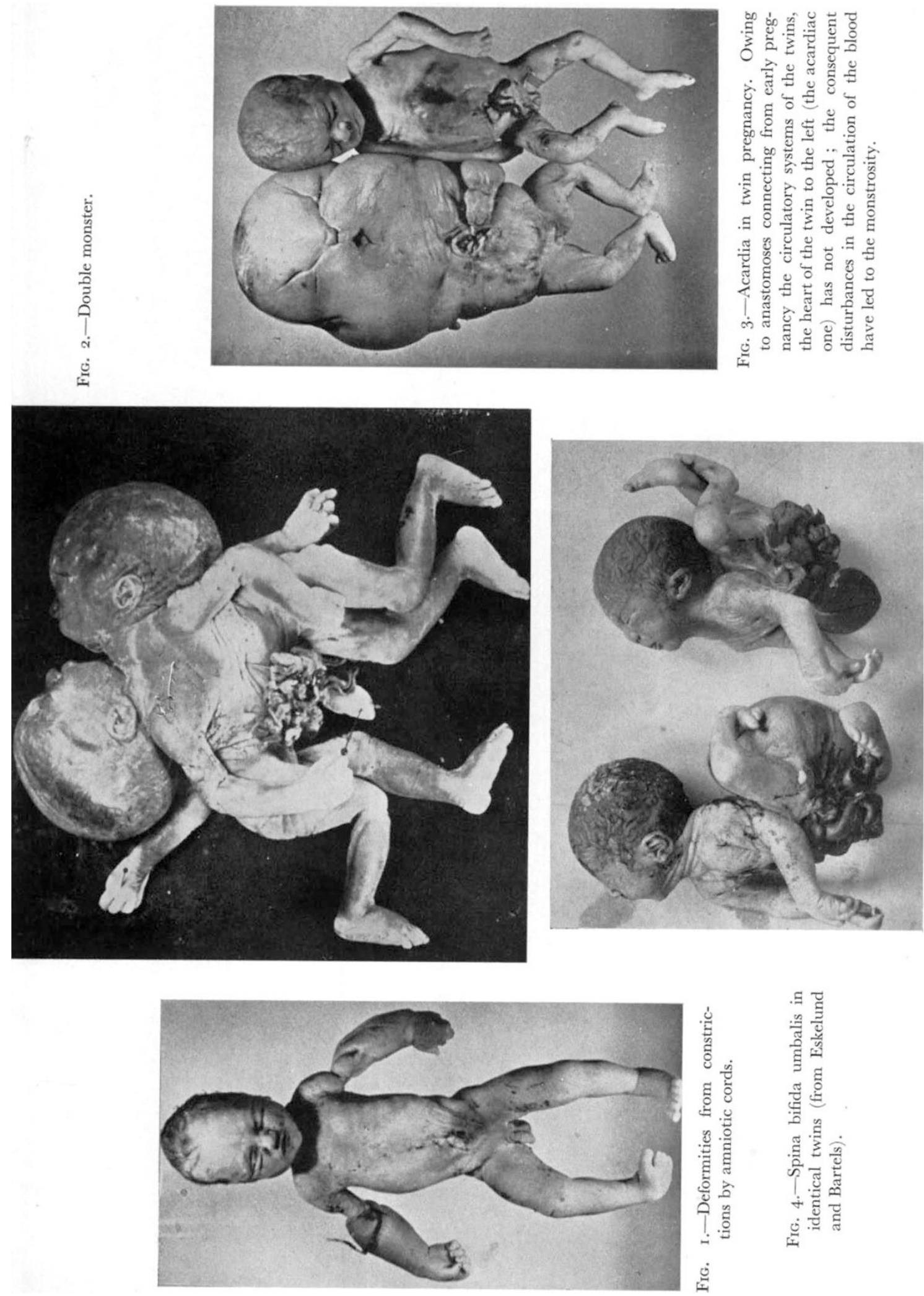


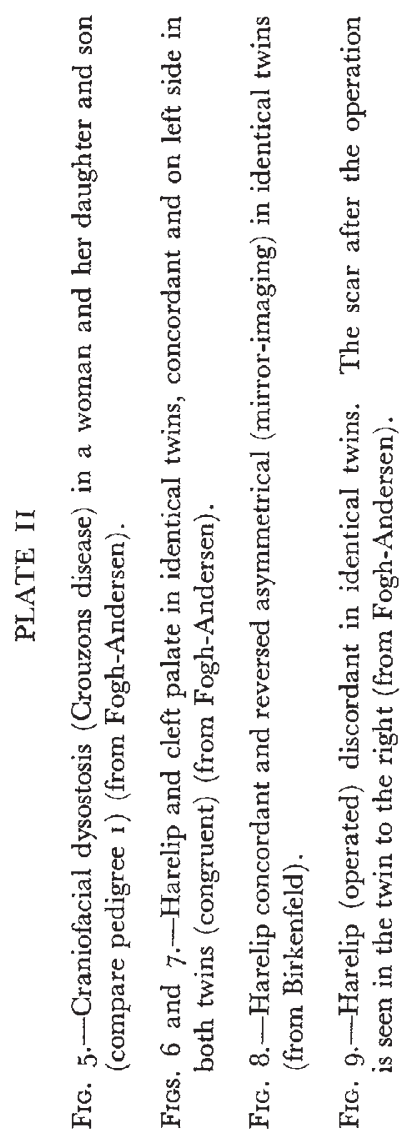




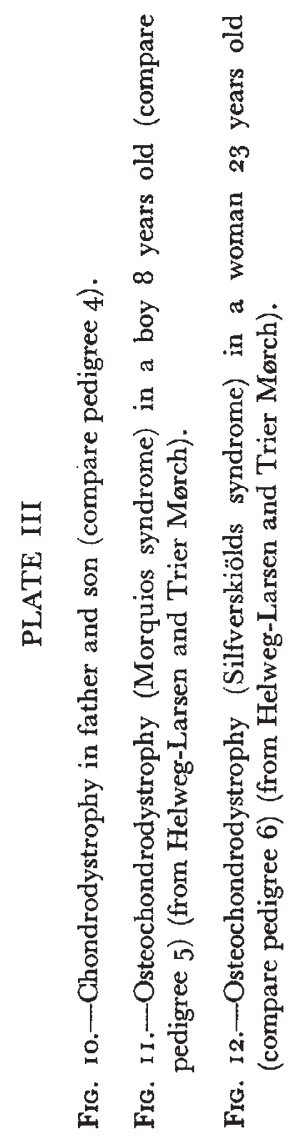




\section{PIATE III}
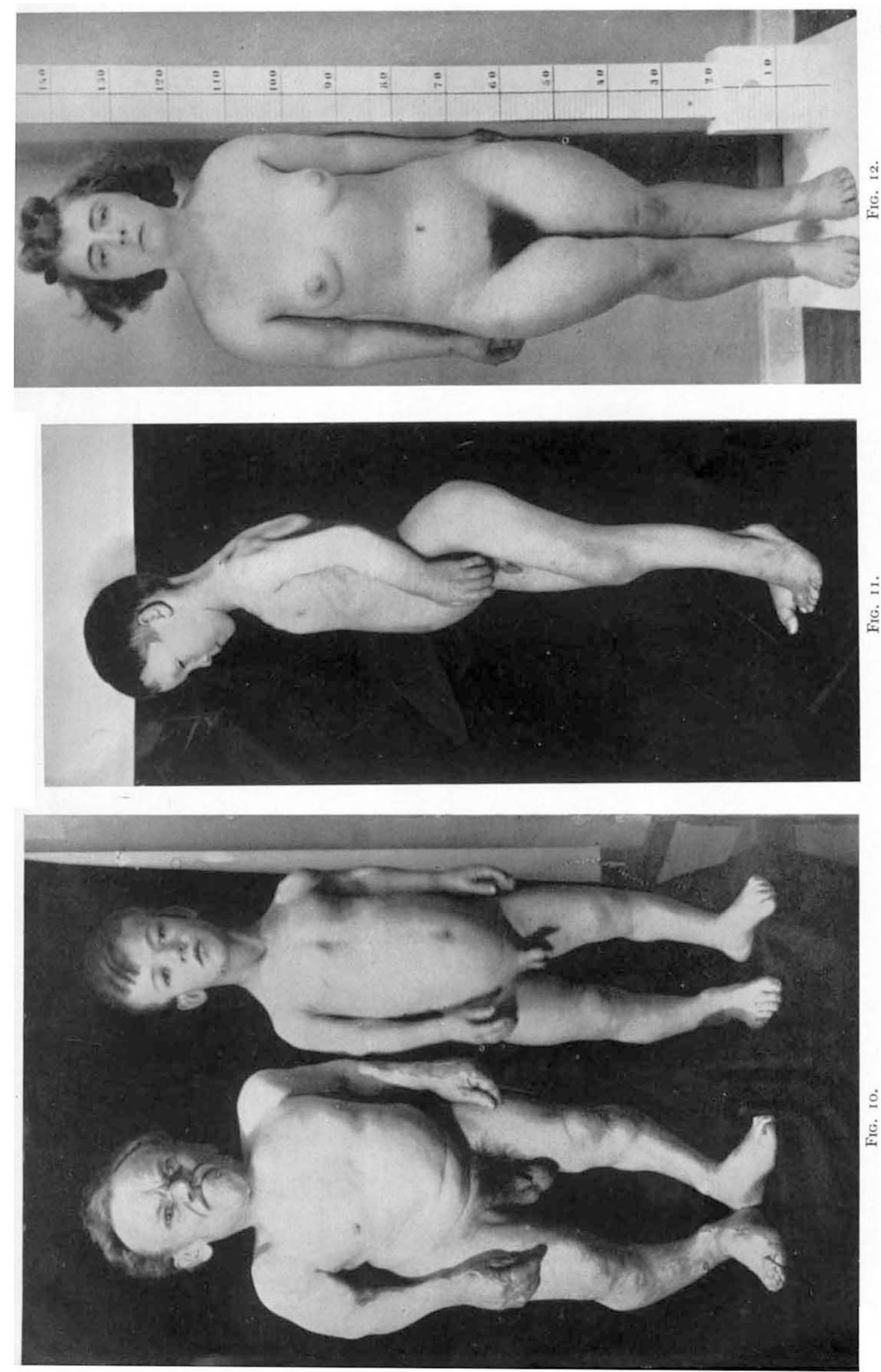


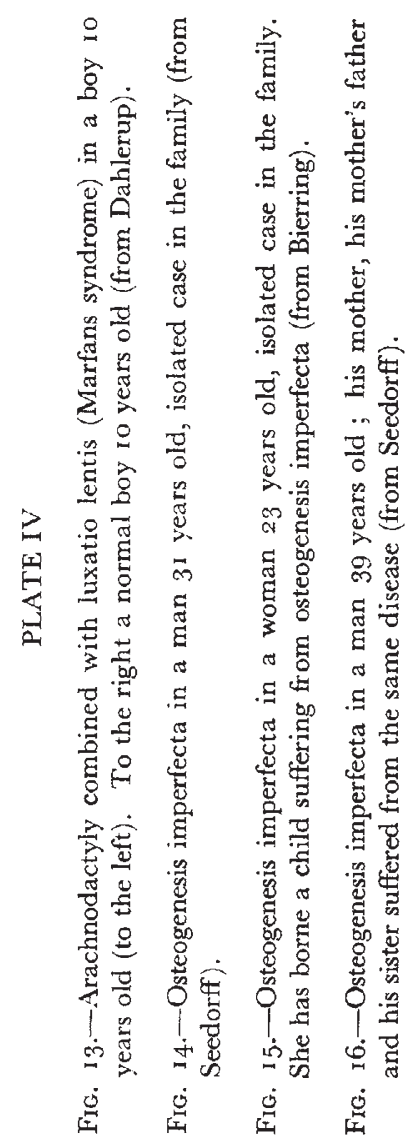



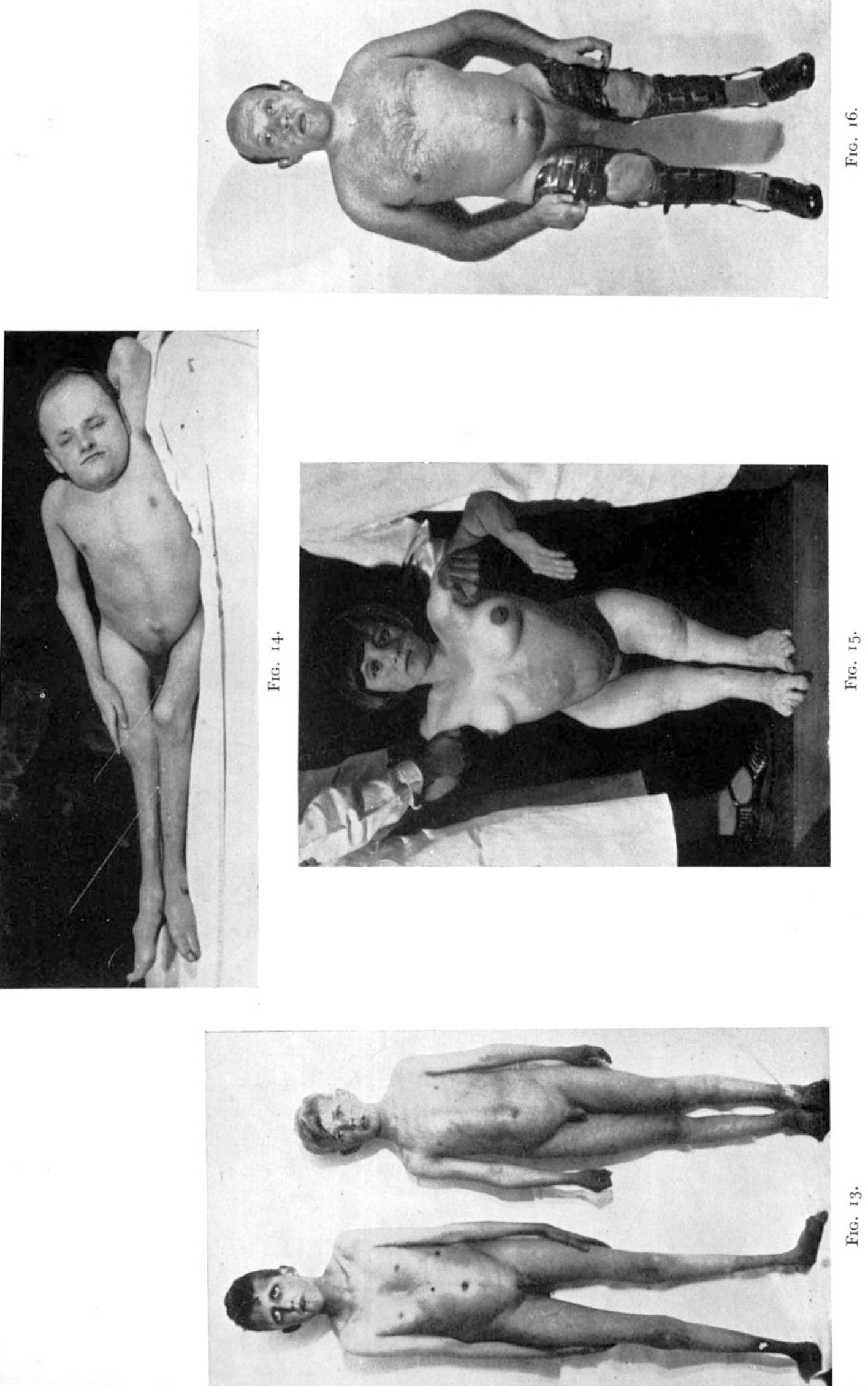


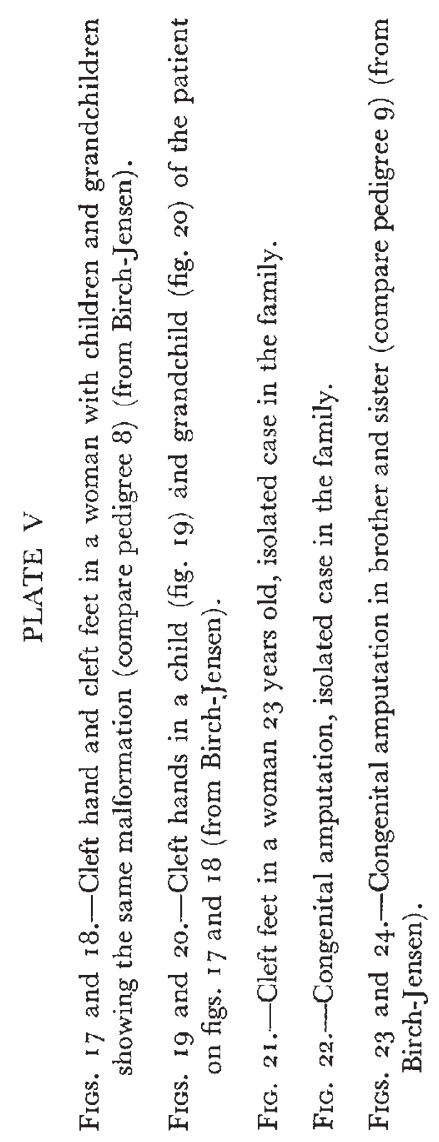


PLATE V
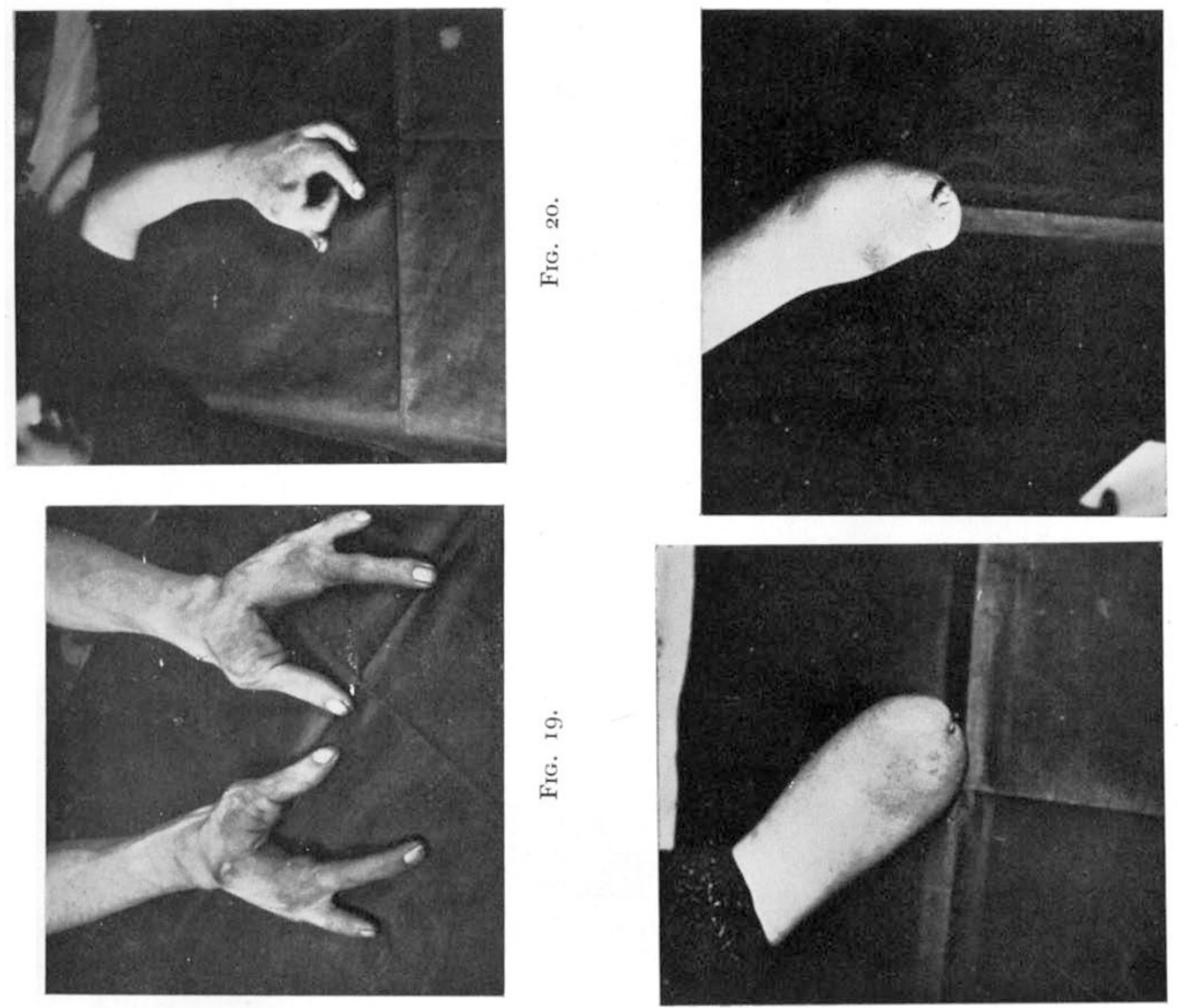

वें

बें
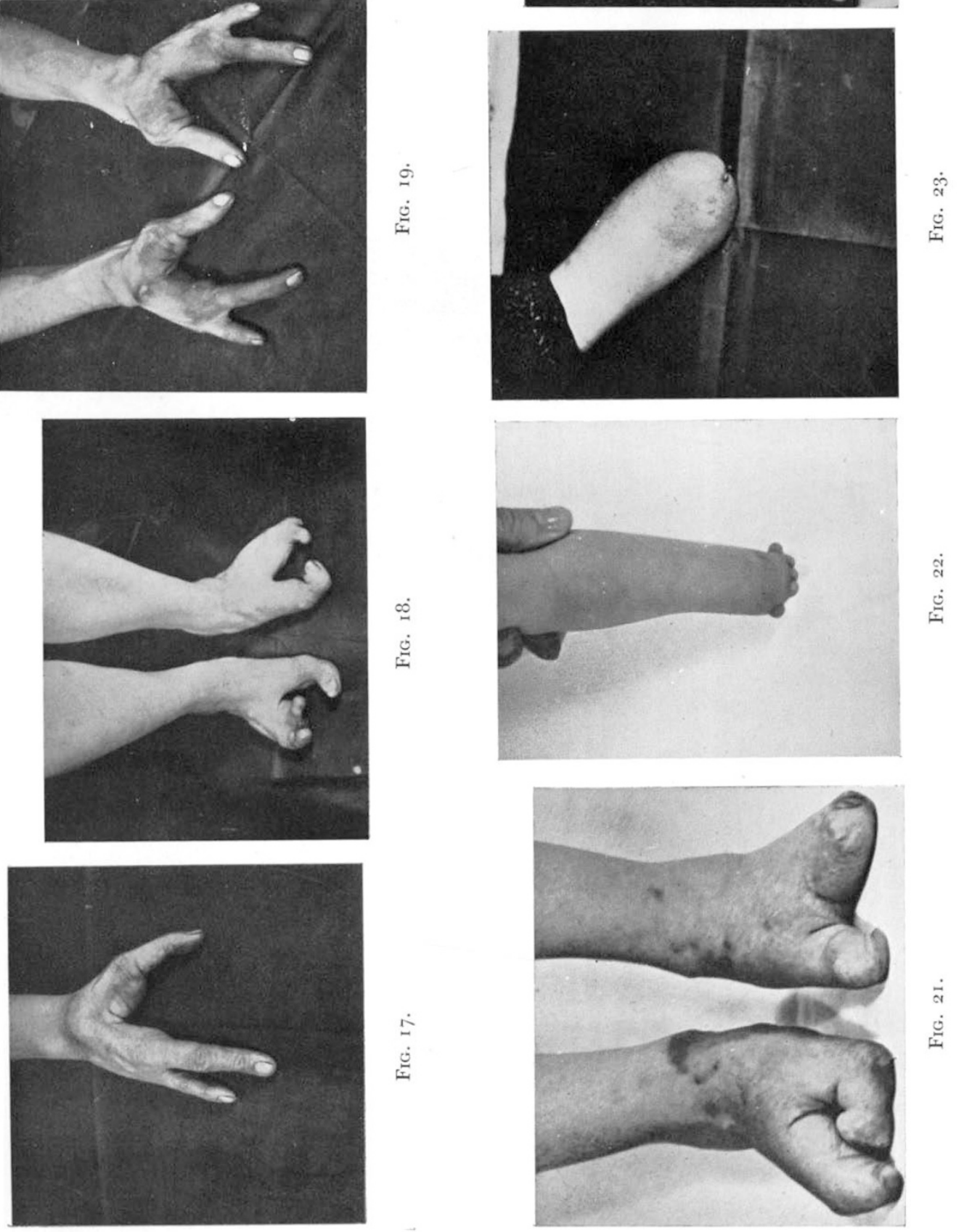
isolated examples in the family (fig. 2I); in about ro per cent., however, the malformation was inherited as a dominant character through several generations (pedigree 8 and pl. V, figs. I 7-20).

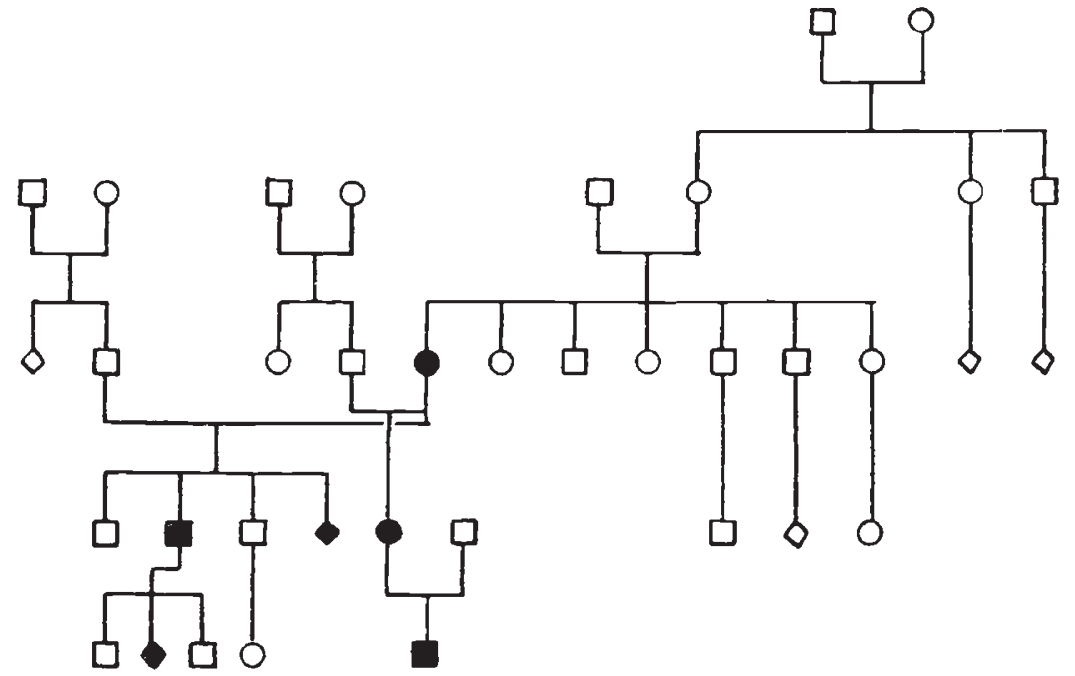

Pedigree 8. Cleft hands and cleft feet as a dominant character.

Still less dependent on hereditary factors are the congenital amputations of the extremities. Birch-Jensen examined about 140 families with at least one case of congenital amputation and nearly every case appeared isolated as a single case in the family (fig. 22) ; in about 10 of the families a malformation was found in more or less

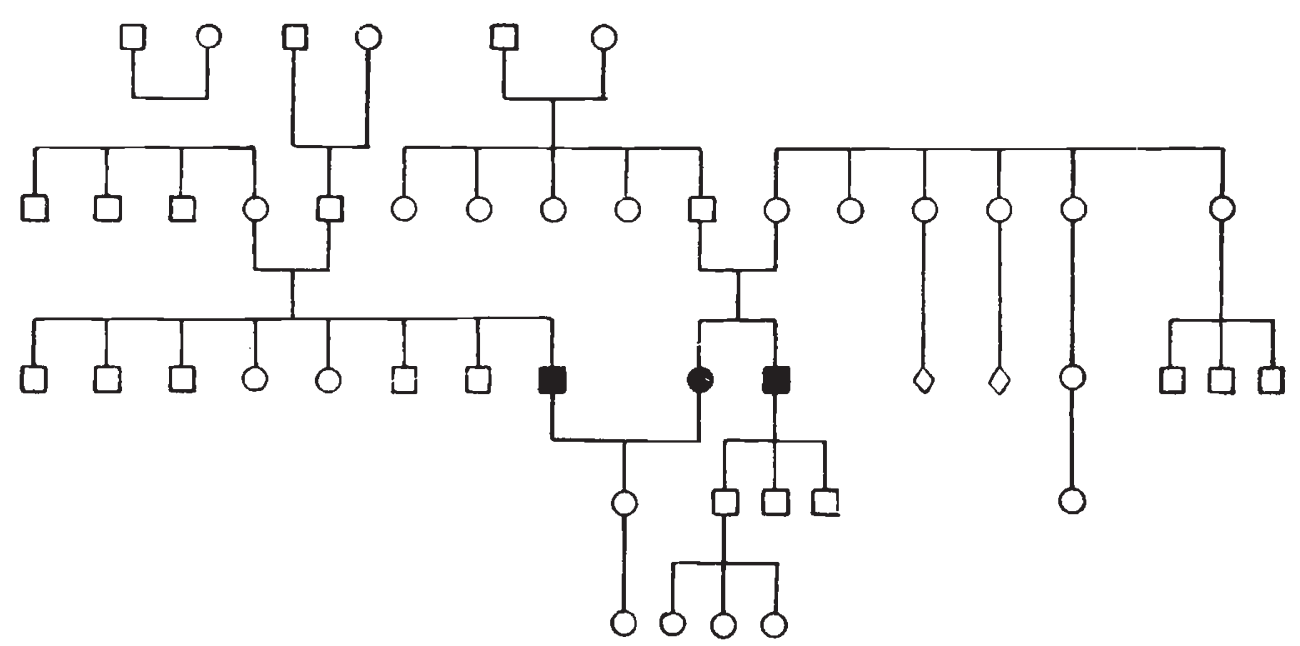

Pedigree 9. Congenital amputation (recessive ?). (Pedigrees 8 and 9 from Birch-Jensen).

distant relatives. Rather exceptional is the family demonstrated in pedigree 9, and figs. 23-24, showing congenital amputation in a 
brother and a sister. I 42 patients with congenital amputation had altogether borne 76 children, and none of these 76 children suffered from congenital amputations or other malformations. The malformed sister in pedigree 9 married a man with a congenital amputation and still they had a normal daughter and a normal granddaughter. The malformed brother had six normal descendants in two generations.

The more recent Danish studies on hereditary physical malformations and the way in which these lesions are transmitted have now been mentioned to illustrate the methods we use in the Institute of Human Genetics in Copenhagen.

In our genetic register which, as far as possible, is a complete card index covering all the more serious hereditary affections observed in Denmark, we have the starting-point for more thorough investigation into particular fields-in many instances, of the inheritance of a special lesion. The procedure then is as follows: The physician, who is trained as a specialist in the field concerned, makes a thorough investigation of the individual patients with the lesion in question and of their families, partly on the basis of hospital records and other documentary material, partly by travelling about, visiting and examining the individual patients in their homes.

Among similar investigations undertaken with a view to other groups of diseases and carried out by a number of specialists attached to our institute-studies that have been completed already or will be concluded in the near future-the following lesions may be mentioned :-

Medical diseases. Hemophilia, hypertension, nephrosclerosis, diabetes mellitus, gastric and duodenal ulcers, bronchial asthma, situs inversus of the viscera, thyroid diseases.

Cancer. Cancer of the breast, cancer of the uterus, double cancer, leukæmia.

Nervous diseases. Myotonia, progressive muscular dystrophy, spinal muscular atrophy, Huntington's chorea, epilepsy.

Mental diseases. Schizophrenia, tuberous sclerosis, mongoloid idiocy.

Skin lesions. Epidermiolysis bullosa, anhidrosis and neurolabyrinthitis, von Recklinghausen's disease.

Eye lesions. Aniridia, coloboma, buphthalmia, glaucoma, retinitis pigmentosa, Leber's optic atrophy, angiomatosis of the retina.

Ear lesions. Sporadic recessive deaf-mutism, heredolabyrinthic deaf-mutism, otosclerosis.

Besides these investigations of the inheritance of the individual diseases the institute is occupied also with other tasks such as, for instance, investigations of twins and of certain definite groups of the population, e.g. gipsies, prostitutes, some asocial elements, and adopted children. In this way the registration of the hereditary diseases in Denmark is supplemented.

On the basis of the experiences gained in these investigations, the institute exercises its hereditary hygienic or eugenic activity as adviser on questions of sterilisation, induced abortion, marriage, adoption, and of special relief. The material of the registration department has proved to be of much use to this activity.

In the department for experimental pathological genetics investigations on cytology and experimental studies on hereditary diseases occurring in the common experimental animals are carried out. 
The investigations on hereditary malformations mentioned in this paper exemplify the means and methods used in our institute for studying the various groups of hereditary diseases.

\section{SUMMARY}

Investigations on the inheritance of various congenital malformations are described, viz. craniofacial dysostosis, harelip and cleft palate, chondrodystrophy, osteochondrodystrophy, arachnodactylia, Marfan's syndrome, osteogenesis imperfecta, craniorachischisis, cleft hands and feet, ectrodactylia and congenital amputations.

Through the study of these malformations it has been possible to show that the laws of heredity known from experimental genetics apply also to hereditary lesions in man.

BIERRING, K. I933.

\section{REFERENCES}

Acta chir. scand., 70, $48 \mathrm{I}$.

BIRKENFELD, W. 1927.

Beitr. z. klin. Chir. I4I, 257.

DAHLERUP, J. V. I 1942 .

Ugeskrift Leger ro4, 64 .

ESKELUND, V., and BARTELS, E. D. I94I.

Nordisk Medicin $I Y, 175$.

FILSKOV, A. 1941 .

Ugeskrift for Lager 103, 459.

FOGH-ANDERSEN, P. I943.

Nordisk Medicin r8, 993.

FOGH-ANDERSEN, P. I943.

Inheritance of harelip and cleft palate. Copenhagen.

HELWEG-LARSEN, H. F., and MפRCH, E. TRIER. 1945.

Acta path. micr. biol. scand. 22, 335.

HINDSE-NIELSEN, S. 1938.

Acta chir. scand. $80,525$.

KEMP, T. I944.

Acta path. micr. biol. scand. Suppl. LIV, 195.

MORCH, E. TRIER. I $94^{I}$.

Chondrodystrophic dwarfs in Denmark. Copenhagen.

Publications of A. BIRCH-JENSEN and K. SEEDORFF are under preparation. Nearly all the papers cited above are to be found in Opera ex dom. biol. hered. Univ. Haf. vols. $r, 3,4,9, r g$ and $20,1941-48$. 